\title{
Effect of Ambient Sunlight Intensity on the Temporal Phenolic Profiles of Vitis Vinifera L. Cv. Chardonnay During the Ripening Season - A Field Study
}

D. Šebela ${ }^{1,2, *}$, Z. Turóczy ${ }^{1}$, J. Olejníčková ${ }^{1}$, M. Kumšta ${ }^{3}$, R. Sotoláŕ ${ }^{3}$

(1) Laboratory of Ecological Plant Physiology, Global Change Research Institute CAS, Bělidla 986/4a, CZ-60300 Brno, Czech Republic

(2) Institute of Physics and Biophysics, Faculty of Science, University of South Bohemia, Branišovská 1645/31a, CZ-37005 České Budějovice, Czech Republic

(3) Department of Viticulture, Faculty of Horticulture, Mendel University in Brno, Valtická 337, CZ-69144 Lednice, Czech Republic

Submitted for publication: October 2016

Accepted for publication: January 2017

Key words: Abiotic stress, catechin, grape berries, OD $280 \mathrm{~nm}$, UV light, viticulture

Grape phenolics are considered to have a significant impact on wine quality, with their quantity and dynamics being strongly influenced by environmental conditions. We investigated the effect of ambient sunlight on the temporal dynamics of phenolics in cv. Chardonnay under field conditions during the 2012 ripening season, from véraison until harvest. The phenolic profiles of the grapes were monitored at predefined time intervals by using high-pressure liquid chromatography (HPLC) and spectrophotometric (OD) analysis. The obtained concentrations were correlated with the average sunlight intensities preceding the sampling. No significant correlations were found between the hydroxycinnamic acid, hydroxybenzoic acid and stilbene content, in contrast with the strong relationships found between: (i) $\mathbf{O D}_{280 \mathrm{~nm}}$, (ii) catechin, (iii) flavanols and (iv) total polyphenols and the fluctuating dose of ambient sunlight reaching the grapes throughout the ripening season. The light-dependent dynamics of several main phenolic compounds in cv. Chardonnay during the ripening period could help to establish correlation models that increase the applicability of meteorological data in the assessment of optimal phenolic ripeness in modern viticulture.

\section{INTRODUCTION}

Viticulture worldwide is influenced by constant and sometimes drastic changes in many environmental conditions (Fraga et al., 2012). Therefore, a major challenge for wine producers today is to constantly cope with the global changes, both biotic and abiotic, in environmental conditions. Viticulture and climate change are interrelated processes taking place on a global scale in which temperature, precipitation and solar radiation are the main drivers (AbouHussein, 2012). Overexposure to or lack of any of these factors may influence yield and grape quality. This means that the delicate equilibrium between these environmental components has a great effect on the final product.

Sunlight is composed mainly of infrared wavelengths, but also contains a small amount (approx. 8 to $9 \%$; Frederick, 1993) of ultraviolet (UV) light that is harmful to life on Earth (reviewed by Hollósy, 2002). UV light can be divided into three categories, based on their spectral properties: UV-A (315 to $400 \mathrm{~nm}$ ), UV-B (280 to $315 \mathrm{~nm}$ ) and UV-C (100 to $280 \mathrm{~nm}$ ). UV-A radiation is not absorbed by the ozone layer, whereas $\mathrm{UV}-\mathrm{C}$ radiation is completely absorbed. The intensity of UV-B light (which is potentially harmful to plants) reaching the Earth's surface is strongly dependent on the thickness of the ozone layer. Thus, due to a decrease in stratospheric ozone concentrations, there is an increase in ambient UV radiation reaching the surface of the Earth (McKenzie et al., 2003). However, the amount of ambient UV light is also strongly dependent upon spatial and temporal factors, such as season of the year, time of the day, cloud cover, canopy coverage, etc.

The effect of ambient and elevated UV-B light on terrestrial plants has been examined in many studies. Under realistic spectral regimes in field experiments there is a species-specific plant response, including alterations in plant morphology and architecture (Kakani et al., 2003), DNA damage and antioxidant response (Hollósy, 2002), and an effect on photosynthetic efficiency (Burger \& Edwards,

*Corresponding author: E-mail address: sebela.d@czechglobe.cz

Acknowledgements: The authors are thankful to Prof. Jan Třriska and Dr Naděžda Vrchotová, for their helpful discussions and comments. This work was supported by project GA 522/09/1565 and FP7-SME-2010-1-262011-PREMIVM and forms a part of research supported by the Research Infrastructure Project EPPN (FP7; Grant Agreement No. 284443). Participation of the first and third author was supported by the Ministry of Education, Youth and Sports, Czech Republic (grant numbers L01415 and LM2015061) 
1996). Still, perhaps the most common plant response to ambient and elevated UV-B radiation is the production of UV-absorbing compounds, such as phenolic compounds (Agati et al., 2009).

Grapevine (Vitis vinifera L. subsp. vinifera Hegi, 1753) phenolics are important quality components contributing not only to the taste and mouthfeel properties of wines, but also to the colour. The phenolic composition of grapes and/or wines is not only strongly cultivar dependent, but can also be influenced by, for example, environmental conditions (reviewed by Teixeira et al., 2013) or winemaking technologies, extraction parameters, as well as chemical reactions taking place during wine fermentation (Ramos et al., 1999). Grapevine phenolics are divided into two groups: non-flavonoid compounds and flavonoids. From a wine quality perspective, the major non-flavonoid compounds are hydroxycinnamic acids (HCA), hydroxybenzoic acids (HBA) and stilbenes. Flavonoids represent a source of antioxidants in grapevine (Conde et al., 2007) and include classes of (i) flavanols, particularly relevant for astringency in the final product, (ii) flavonols, which may influence bitterness, and (iii) anthocyanins (e.g. malvidin-3-O-glucoside), which separate red varieties from white varieties. Several of these phenolic compounds are known for their health benefits, since they possess antiallergic, anti-inflammatory, antiviral and antioxidant activities (reviewed by Pal \& Verma, 2013). Moreover, the importance of some phenolic compounds and their possible protective role against, for example, grapevine yellows (Rusjan et al., 2012a) and downy mildew (Šebela et al., 2014), also has been suggested.

Grapevines have to cope with relatively great doses of ambient radiation in the field during their life cycle and throughout each ripening season. At the same time, irradiance reaching each grape berry is affected by fluctuations in the intensity, spectral quality and periodicity of incoming light (Frankhauser \& Staiger, 2002). Such imbalances in incident light can cause changes in the synthesis of phenolic compounds and the resulting fluctuating trend in their concentrations during the ripening season. Based on the photo-protective role of phenolic compounds in grape berries (De Orduña, 2010), the light dependency of the synthesis of phenolic compounds has been tested across grapevine cultivars by two classical approaches, i.e. by shading (Price et al., 1995; Spayd et al., 2002; Downey et al., 2004; Adams, 2006; Friedel et al., 2015) and by UV light filtering (Keller \& Torres-Martinez, 2004; Berli et al., 2008) experiments. Both attempts showed the significance of UV radiation in these processes. However, very few studies have reported the possible effects of a combination of both UV and visible light on the synthesis of these compounds (Schultz, 2000; Kolb et al., 2001; Schreiner et al., 2012), or their seasonaltemporal characteristics. Even though the dependence of the phenolic content on the grape developmental stages has been documented well (Downey et al., 2003; Doshi et al., 2006; Conde et al., 2007), real-time on-site data concerning the relationship between ambient sunlight intensity, phenolic profiles and the berry development throughout the ripening process is scarce. Thus, the objective of this study was to determine the effect of ambient sunlight intensity on the maturation and subsequent phenolic profiles of grapevine berries in the common white cultivar Chardonnay during the ripening season.

\section{MATERIALS AND METHODS \\ Plant material}

The study was carried out in the experimental vineyard of the Department of Viticulture and Oenology located in Lednice, Czech Republic (48 $\left.47^{\prime} 24.16^{\prime \prime} \mathrm{N} ; 16^{\circ} 47^{\prime} 53.61^{\prime \prime} \mathrm{E}\right)$, during the ripening season in 2012. The position of the vineyard was open, easily accessible by sunlight, the land mostly flat but with a slight incline to the southwest. The soil of the vineyard has been characterised as sandy, containing 20 to $24 \%$ clay particles. For experimental purposes, the leaves were removed to allow full sun exposure of all clusters used in this study. Sampling was done randomly from ca. 250 uniform plants; the time course of the monitoring process was selected according to Coombe (1992), i.e. early ripening season corresponding to the véraison $(\mathrm{BBCH} 82)$ and maturity to the harvest $(\mathrm{BBCH} 93)$ phenological growth stages (Lorenz et al., 1995). The Chardonnay grapevine cultivar was sampled at predefined time intervals, i.e. alternatively each second and fifth day, in the period between August and October. At each date, samples were collected in the vineyard at the same time $(08: 00 \mathrm{am})$ and immediately transported to the laboratory. To attenuate environmental differences other than the influence of ambient sunlight intensity, clusters were always taken from the first fruit-bearing shoot with a southeast orientation. To prevent sample drying, each cluster was placed in a plastic bag and transported at a controlled temperature of $15^{\circ} \mathrm{C}$.

\section{Extraction of polyphenols}

For the chemical analysis, two clusters were selected for each sampling date. Nine berries were randomly cut from each of these two clusters, taking into account that they were equally distributed in the whole cluster. The whole grape berry extracts (including skin, flesh and seeds) were prepared as follows: from the eighteen berries sampled, six groups containing three random berries were extracted, i.e. smashed in a solution containing 90\% methanol $(\mathrm{MeOH})$ and $1 \mathrm{mM}$ potassium metabisulphite $\left(\mathrm{K}_{2} \mathrm{H}_{2} \mathrm{O}_{5}\right)$ at a ratio of 1:1 (mg berry/ml MeOH $+\mathrm{K}_{2} \mathrm{H}_{2} \mathrm{O}_{5}$; Kumšta et al., 2012), and left in the dark at room temperature for two weeks. The resultant six extracts were used to calculate the average concentrations for each sampling date. Following extraction, the homogenate was centrifuged at $15000 \mathrm{rpm}$ for $10 \mathrm{~min}$. Supernatants were than filtered through $0.45 \mu \mathrm{m}$ Millipore filters (Merck Millipore, Prague, Czech Republic) and stored at $-20^{\circ} \mathrm{C}$ until the analysis.

\section{HPLC analysis of polyphenols}

Two similar HPLC methods were used:

1. Percentage ratio and concentrations of total polyphenols HPLC analysis was performed using a digital highpressure system LC-1A with system controller SCL-10Avp (Schimadzu, Japan). For the separation, a Polymer IEX H form $10 \mathrm{~mm}$ packing, $250 \times 8 \mathrm{~mm}+10 \times 8 \mathrm{~mm}$ column (Watrex, Czech Republic) was used. To shorten the analysis time and facilitate separation, the column was kept at $60^{\circ} \mathrm{C}$ during analysis, using a column thermostat with a manual 
spraying valve Rheodyne CTO-10Acvp (Shimadzu, Japan). Isocratic elution was used with $2 \mathrm{mM}$ of $\mathrm{H}_{2} \mathrm{SO}_{4}$ in the mobile phase. The applied flow rate, provided by a pump (LC-10 Advp) with two channels, was $0.75 \mathrm{ml} / \mathrm{min}$; the injected sample volume was $20 \mu \mathrm{l}$.

2. A time trend of total polyphenols analysis was performed using a 1200 Infinity Series Instrument (Agilent Technologies, USA), equipped with a thermostat and auto sampler. For the separation, Alltech Alltima C18 $3 \mu \mathrm{m}$ particle size reversed phase column 150 × $3 \mathrm{~mm}$ (Fisher Scientific, USA) was used with the following mobile phase: $50 \%$ acetonitrile, $15 \mathrm{mM}$ $\mathrm{HClO}_{4}, 10 \%$ methanol as solvent $\mathrm{A}$, and $15 \mathrm{mM} \mathrm{HClO}_{4}$ as solvent $\mathrm{B}$, with an equal flow rate of $0.5 \mathrm{ml} \mathrm{min}^{-1}$. The gradient employed was as follows: $0 \mathrm{~min}, 2 \% \mathrm{~A}, 20 \mathrm{~min}$, $26 \%$ A, $30 \mathrm{~min}, 45 \%$ A, $35 \mathrm{~min}, 70 \%$ A, $37 \mathrm{~min}, 100 \%$ A, 39 min $0 \%$ A, $50 \mathrm{~min}, 2 \%$ A. During the analysis, the column was kept at $60^{\circ} \mathrm{C}$ to shorten the separation time. The different phenolic compounds were identified by comparison with the pure standards based on their retention times and the UV-VIS spectra (Table 1). HPLC grade standards for the phenolic compounds of interest were purchased from SigmaAldrich (USA) and PhytoPlan (Germany); the quantification of phenolic concentration was done on the basis of the calibration curves of these standards.

\section{Reagents and solvents}

Reagents constituting the mobile phase were purchased as follows: methanol (Chromservis, Czech Republic); acetonitrile (Chem-Lab NV, Belgium); and perchloric acid (Acros Organics, Czech Republic). All these reagents were HPLC pure.

\section{Spectroscopic analysis}

Spectroscopic analysis for each extract was carried out by using spectrophotometer SPECORD 210 Plus BU (Analytic Jena AG, Germany). The concentration of total phenolics was obtained by recording absorbance at $280 \mathrm{~nm}\left(\mathrm{OD}_{280}\right.$, Pirie \& Mullins, 1976).

\section{Measurement of light intensity}

The amount of solar radiation in the experimental field was recorded using a standard Campbell-Stokes sunshine recorder (heliograph). To maintain uniformity of the light measurements throughout the experiment, the instrument was placed $1 \mathrm{~m}$ above ground, at a distance of circa $50 \mathrm{~m}$

TABLE 1

Selected phenolic compounds detected by HPLC.

\begin{tabular}{|c|c|c|c|}
\hline Class & Compound & Detection wavelength (nm) & Retention time (min) \\
\hline \multirow[t]{2}{*}{ Flavanols } & $(+)$ - catechin & $200 \mathrm{~nm}$ & 8.1 \\
\hline & (-)- epicatechin & $200 \mathrm{~nm}$ & 10.5 \\
\hline \multirow[t]{16}{*}{ HCA, HBA+ stilbenes } & gallic acid $^{\mathrm{HBA}}$ & $275 \mathrm{~nm}$ & 2.2 \\
\hline & protocatechuic acid ${ }^{\mathrm{HBA}}$ & $260 \mathrm{~nm}$ & 3.9 \\
\hline & 4-OH benzoic acid ${ }^{\mathrm{HBA}}$ & $260 \mathrm{~nm}$ & 6.3 \\
\hline & cafftaric acid ${ }^{\mathrm{HCA}}$ & $325 \mathrm{~nm}$ & 6.4 \\
\hline & coutaric acid ${ }^{\mathrm{HCA}}$ & $310 \mathrm{~nm}$ & 8.5 \\
\hline & vanillic acid ${ }^{\mathrm{HBA}}$ & $260 \mathrm{~nm}$ & 8.6 \\
\hline & caffeic acid $^{\mathrm{HCA}}$ & $325 \mathrm{~nm}$ & 8.6 \\
\hline & syringic acid ${ }^{\mathrm{HBA}}$ & $275 \mathrm{~nm}$ & 10.1 \\
\hline & fertaric acid ${ }^{\mathrm{HCA}}$ & $325 \mathrm{~nm}$ & 10.1 \\
\hline & coumaric acid $^{\mathrm{HCA}}$ & $310 \mathrm{~nm}$ & 11.3 \\
\hline & ferulic acid ${ }^{\mathrm{HCA}}$ & $325 \mathrm{~nm}$ & 13.7 \\
\hline & trans-piceid ${ }^{\text {stilbenes }}$ & $310 \mathrm{~nm}$ & 15.5 \\
\hline & piceatannol ${ }^{\text {stilbenes }}$ & $325 \mathrm{~nm}$ & 16.3 \\
\hline & cis-piceid ${ }^{\text {stilbenes }}$ & $285 \mathrm{~nm}$ & 19.5 \\
\hline & trans-resveratrol ${ }^{\text {stilbenes }}$ & $310 \mathrm{~nm}$ & 20.6 \\
\hline & cis-resveratrol ${ }^{\text {stilbenes }}$ & $285 \mathrm{~nm}$ & 23.3 \\
\hline \multirow[t]{7}{*}{ Flavonols } & rutin & $350 \mathrm{~nm}$ & 18.0 \\
\hline & quercetin 3- $\beta$-D-glucoside & $350 \mathrm{~nm}$ & 18.2 \\
\hline & myricetin & $370 \mathrm{~nm}$ & 20.2 \\
\hline & quercitrin & $350 \mathrm{~nm}$ & 20.6 \\
\hline & quercetin & $370 \mathrm{~nm}$ & 24.5 \\
\hline & kaempferol & $370 \mathrm{~nm}$ & 27.4 \\
\hline & isorhamnetin & $370 \mathrm{~nm}$ & 27.9 \\
\hline
\end{tabular}

HCA-hydroxycinnamic acids

HBA-hydroxybenzoic acids 
from the experimental field, where the shading of the sphere by the entire canopy was not a limiting factor. The device itself consisted of the sphere made from annealed optical glass and the recording sheet. Sun intensity was recorded to the sheet continuously, via a sunbeam coming from the sphere; the record itself was separated into 30 min blocks. Light intensity was than calculated from these 30 min blocks as an average for the whole day $\left(\mathrm{W} / \mathrm{m}^{2}\right)$. For experimental purposes, daily average light intensity was calculated at several predefined time intervals (i.e. day of experiment (DE)) and as an average of the daily means up to six days before the experiment (6DE). Calculated light intensities were directly correlated with the particular phenolic profiles of grape berries obtained by means of HPLC and spectrophotometric analysis for each sampling date.

\section{Weather data}

Day length, temperature extremes and/or averages and precipitation patterns for the 2010, 2011 and 2012 seasons (Table 2) were obtained from a weather station situated directly in the vineyard.

\section{Data analysis}

Open LAB CDS ChemStation software (Agilent Technologies, USA) and LC solution software (Shimadzu, Japan) were used to integrate chromatographic peaks, to create standard calibration curves and to calculate the real concentrations of selected phenolic compounds. The significance of the differences in the concentrations between véraison and harvest was determined by $\mathrm{t}$-test; mean, standard error, correlations and covariance analysis were determined; the significance of the correlation coefficients was tested by regression analysis, ANOVA; and covariance was tested by means of the Pearson coefficient, MS Excel.

\section{RESULTS AND DISCUSSION}

At the onset of véraison, several biochemical changes start to happen in grape berries: an increase in berry size and sugar accumulation, followed by a decrease in acid levels, is perhaps the most important and trivial. However, the optimal physiological ripeness is a far more complex phenomenon that involves changes in the concentrations of several secondary metabolites, which have a significant impact on the resulting wine quality. As harvest gradually approaches, changes in weather conditions (Table 2) and modifications in phenolic content are registered. To compare overall changes in the main groups of phenolic compounds, these are graphically interpreted by means of (i) percentage ratio to total polyphenol content (Fig. 1A) and (ii) the real concentrations (Fig. 1B) at the véraison stage (white columns) and at technological ripening, before harvest (black columns). Since the extraction procedure (i.e. effect of the solvent concentration and/or contact time) could largely influence the determination of phenolics in grape samples (Gambuti et al., 2009), a verified method for whole-berry extraction commonly used in our laboratory (see materials and methods; Kumšta et al., 2012) was used throughout the experiment. Since the method itself is carried out in the dark, with no access to oxygen and by using $\mathrm{SO}_{2}$, no significant changes in the composition of phenolic compounds were

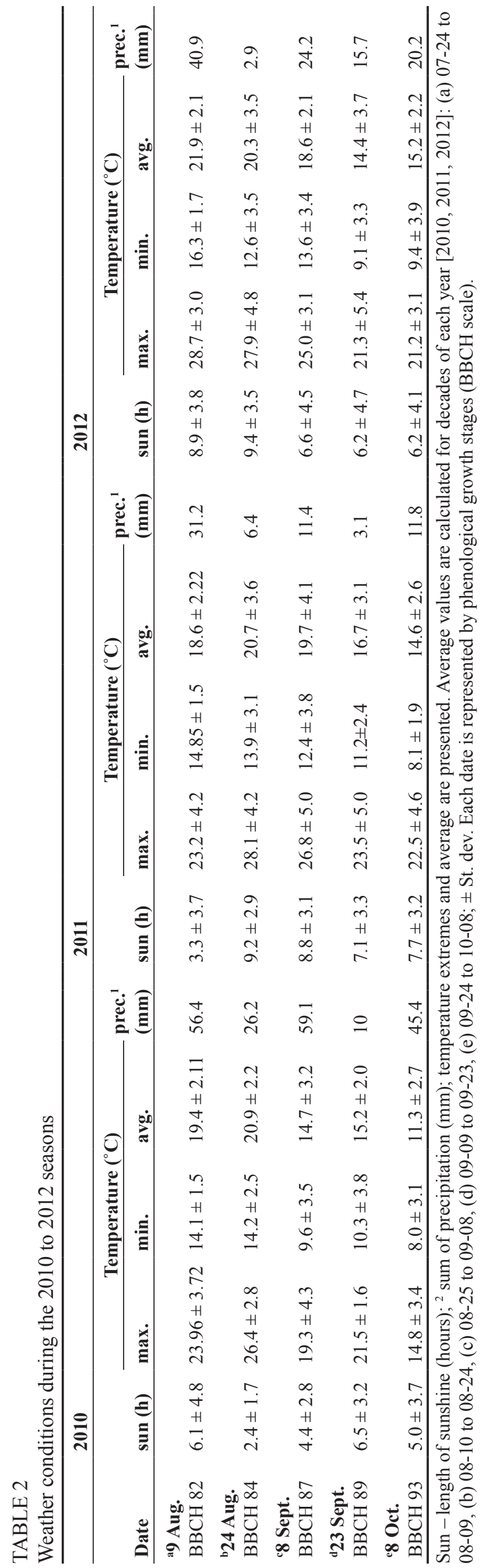




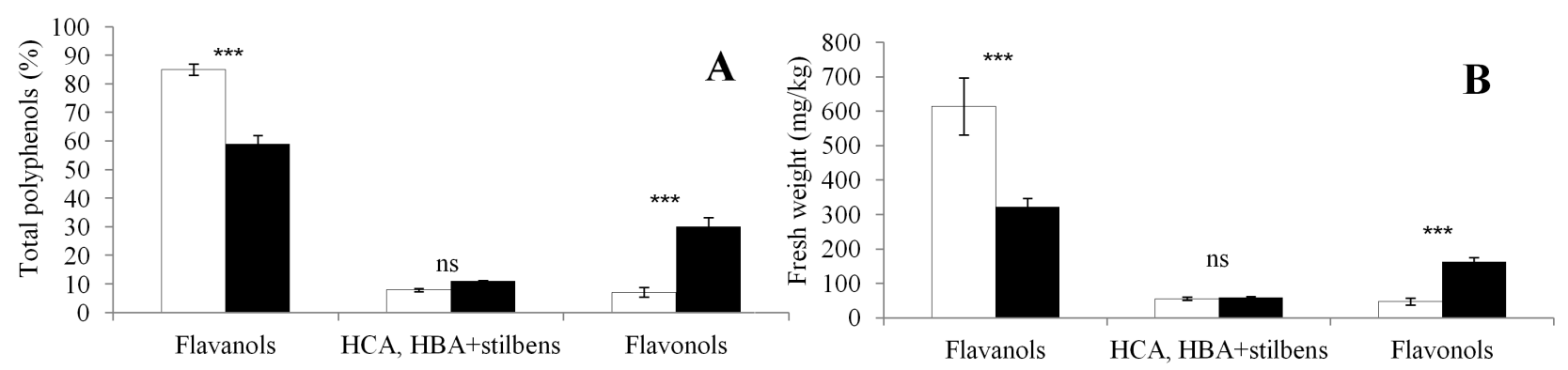

FIGURE 1

Mean values of representative plant phenolics of cv. Chardonnay, expressed as (i) a percentage ratio of $\Sigma$ polyphenols [A] and (ii) real concentrations $[\mathrm{B}]$; at véraison $[\square]$ and before harvest [ $\mathbf{\square}]$. Chemical analysis was performed using a HPLC system. Columns represent the average value of four measuring dates for véraison and before harvest during the ripening season of 2012. Error bars show standard error of the mean $(\mathrm{n}=24, \mathrm{SEM}) . \mathrm{ns}, *, * *, * * *$ - non-significant or significant at probability level of $5 \%, 1 \%$ and $0.1 \%$ respectively.

expected; moreover, no significant changes were found between samples measured in the second and fourth week of extraction (data not shown).

Several reports have shown how the phenolic profiles of grapes change during ripening (e.g. Kennedy et al., 2000, 2002; Adams, 2006) and/or how UV light can influence the synthesis and production of these compounds (e.g. Versari et al., 2001; Kolb et al., 2003; Berli et al., 2008), which are important for wine quality. In the present study, total polyphenol content decreased significantly, from ca. $770 \mathrm{mg} /$ $\mathrm{kg}$ to approx. $540 \mathrm{mg} / \mathrm{kg}$ fresh weight. This decrease of over $25 \%(\mathrm{P}<0.001)$ in the percentage ratio of total polyphenol content is in good agreement with the results described by, for example, Kennedy et al. (2000), Pena-Neira et al. (2004) and Ivanova et al. (2011). The recorded, general trend presented in the literature is a decrease and later a stabilisation of the flavanol content in grapes, which agrees with our observations. It should be noted that, in the early ripening season (véraison), almost $90 \%$ of total polyphenols (stored in the skin and seeds (Fanzone et al., 2011)) are represented by flavanols - catechin and epicatechin (Table 1). However, during ripening there is evidence of a decrease in the levels of free flavanols, together with an increase in the levels of other derivatives (Perez-Magarino \& Gonzalez-San Jose, 2004), corresponding to a ca. $25 \%(\mathrm{P}<0.001)$ increase in (a) flavonols and (b) HCA, HBA + stilbenes, the non-flavonoid compound content found in this study (Fig. 1A).

The increase in flavonol content from 40 to $160 \mathrm{mg} / \mathrm{kg}$ $(\mathrm{P}<0.001$, Fig. 1B) observed during this experiment (approx. $23 \%, \mathrm{P}<0.001$, of the total polyphenol ratio, Fig. 1A) corresponds to the increased flavonoid biosynthetic pathway in grapevine during the ripening process. This pathway has been well characterised in berry skins and seeds (Bogs et al., 2006). In accordance with Rusjan et al. (2012a; 2012b) and/ or Rusjan and Mikulič-Petkovšek (2015), the most dominant compounds of the flavonol group (Table 1) shown in our experiment were found to be quercetin 3- $\beta$-D-glucoside and rutin, with a significant increase from 16 to $97 \mathrm{mg} / \mathrm{kg}$ and 21 to $30 \mathrm{mg} / \mathrm{kg}$ respectively ( $\mathrm{P}<0.001$, Fig. 1B).

Non-flavonoids compounds (HCA, HBA + stilbenes, Table 1) showed the smallest, non-significant changes throughout the entire ripening season (ca. 3\% increase, $\mathrm{P}>0.05$, from 55 to ca. $60 \mathrm{mg} / \mathrm{kg}$, Figs $1 \mathrm{~A}$ and $1 \mathrm{~B}$ ). As shown by Singleton et al. (1978), HCAs are present mostly in the flesh of the grape berries. A major compound and representative member of the HCAs and HBAs in this study (caftaric acid) did not show any significant change in concentration before harvest and in the early ripening season $(\mathrm{P}>0.05$, ca. $40 \mathrm{mg} / \mathrm{kg})$, which is in accordance with previous results obtained by our group (data not shown). In contrast to HCA and HBA, which were present mostly in the berry flesh, the majority of stilbenes have been reported to be found in the grape skin (Versari et al., 2001). In our study, a visible increase in the concentration of the main compound from the group of stilbenes (resveratrol, Table 1) was observed between harvest and the onset of véraison ( 0.27 to $0.69 \mathrm{mg} / \mathrm{kg}$ ), showing a similar trend to that found by Guifree (2013).

Changes in the content of phenolic compounds during the ripening season of 2012 did not follow a clear, well-defined trend (Fig. 2). Instead, the curves revealed big variations in the phenolic contents between different time points. These differences in concentration could be explained by 'dateto-date' fluctuations in critical environmental conditions (reviewed by Teixeira et al., 2013). As reported by Bergqvist et al. (2001), the temperature increases linearly with sun exposure, and its optimum for berry growth is in the range of 25 to $30^{\circ} \mathrm{C}$ (Hale \& Buttrose, 1974). With increasing sunlight intensity, however, there is a related temperature effect. This possible temperature effect (see differences in three ripening seasons, Table 2), as one of the most critical factors connected to the phenolic ripeness of grape berries, was maximally attenuated by the sampling procedure used in this study (see materials and methods). Even though the grapevines' biochemical pathways are mutually light and temperature sensitive (Kliewer, 1970), the light regime reportedly plays a more crucial role during berry ripening compared to the other environmental conditions (Dokoozlian \& Kliewer, 1996), and thus has been named as a key factor influencing the synthesis of the phenolic compounds. Since the shading caused by leaf area density and canopy architecture (Gladstone \& Dokoozlian, 2003) 
could influence the light reaching the clusters, the usual agro-technical leaf-removal treatments were applied prior to the experiment to minimise the effect of canopy shading (Reynolds et al., 1995). Similarly, to avoid the effect of vineyard orientation and/or microclimatic influences inside the vineyard itself (Pereira et al., 2006), the sampling setup was adapted according to the experiment's purpose (see materials and methods).

Average ambient light intensity (Fig. 2) and/or day length (Table 2) showed decreasing trends throughout the entire ripening season in 2012. The maximum level, at the beginning of the season (August, ca. $300 \mathrm{~W} \cdot \mathrm{m}^{-2}$ ), was followed by a few minima during wet and cloudy days (Table 2), when light intensity dropped to ca. $100 \mathrm{~W} \cdot \mathrm{m}^{-2}$, followed by reaching a maximum and decreasing slowly towards 220, 160 and $100 \mathrm{~W} \cdot \mathrm{m}^{-2}$ (Fig. 2, 1DE) at the end of the season (October), respectively. The maximum average light intensity of $300 \mathrm{~W} \cdot \mathrm{m}^{-2}$ was proportional to a total sunshine of 12 hours per day, in contrast to $100 \mathrm{~W} \cdot \mathrm{m}^{-2}$, which corresponded to 0.3 hours of total sunshine per day (Table 2). To investigate the connection between the ambient sunlight intensity and the concentration of the phenolic compounds throughout the ripening season, estimates of the phenolic concentration of wine and grapes $\left(\mathrm{OD}_{280}\right.$; Pirie \& Mullins, 1976) were plotted against the specific amount of solar radiation. In contrast to Pirie and Mullins (1976), however, we used more concentrated methanol for phenolic compound extraction (see materials and methods).
The reason for this was our experimental setup, i.e. whole berry extraction (including skin, flesh and seeds). In fact, dilution caused by the berry flesh causes an identical experimental design as that prescribed in the literature. The same approach, i.e. connection between sunlight intensity and phenolic compounds, was implemented when using the real concentrations measured by HPLC analysis. The mutual dependence between the amount of solar radiation and the relevant concentrations is summarised by the regression coefficients $\left(\mathrm{R}^{2}\right.$, Table 3$)$. As expected, no or very low correlation was found between phenolic concentration and average sunlight intensity measured on the same day as the berries were sampled (day of experiment - DE, Table 3). Due to the consistent, early morning (08:00) sampling, when fluctuations in light intensity were minimal, such changes in the average light could not have had a major influence on the actual concentrations of phenolics. The values of the regression coefficients across the ripening season (Table 3 ) showed an increasing trend up to $3 \mathrm{DE}$, when they either reached a constant value or started to decrease. No significant correlation $(\mathrm{P}>0.05)$ was found in the case of HCA, HBA and stilbenes, where values were in the range of 0.00 to 0.21 . On the other hand, a strong relationship was found between average light intensity at 3DE and: (i) OD $280 \mathrm{~nm}\left(\mathrm{R}^{2}=0.67\right.$, $\mathrm{P}<0.001)$; (ii) catechin $\left(\mathrm{R}^{2}=0.59, \mathrm{P}<0.001\right)$, (iii) flavanols $\left(\mathrm{R}^{2}=0.47, \mathrm{P}<0.01\right)$ and (iv) total polyphenols $\left(\mathrm{R}^{2}=0.41\right.$, $\mathrm{P}<0.01)$. In agreement with our study, Keller and TorresMartinez (2004) showed that flavonols are those phenolic

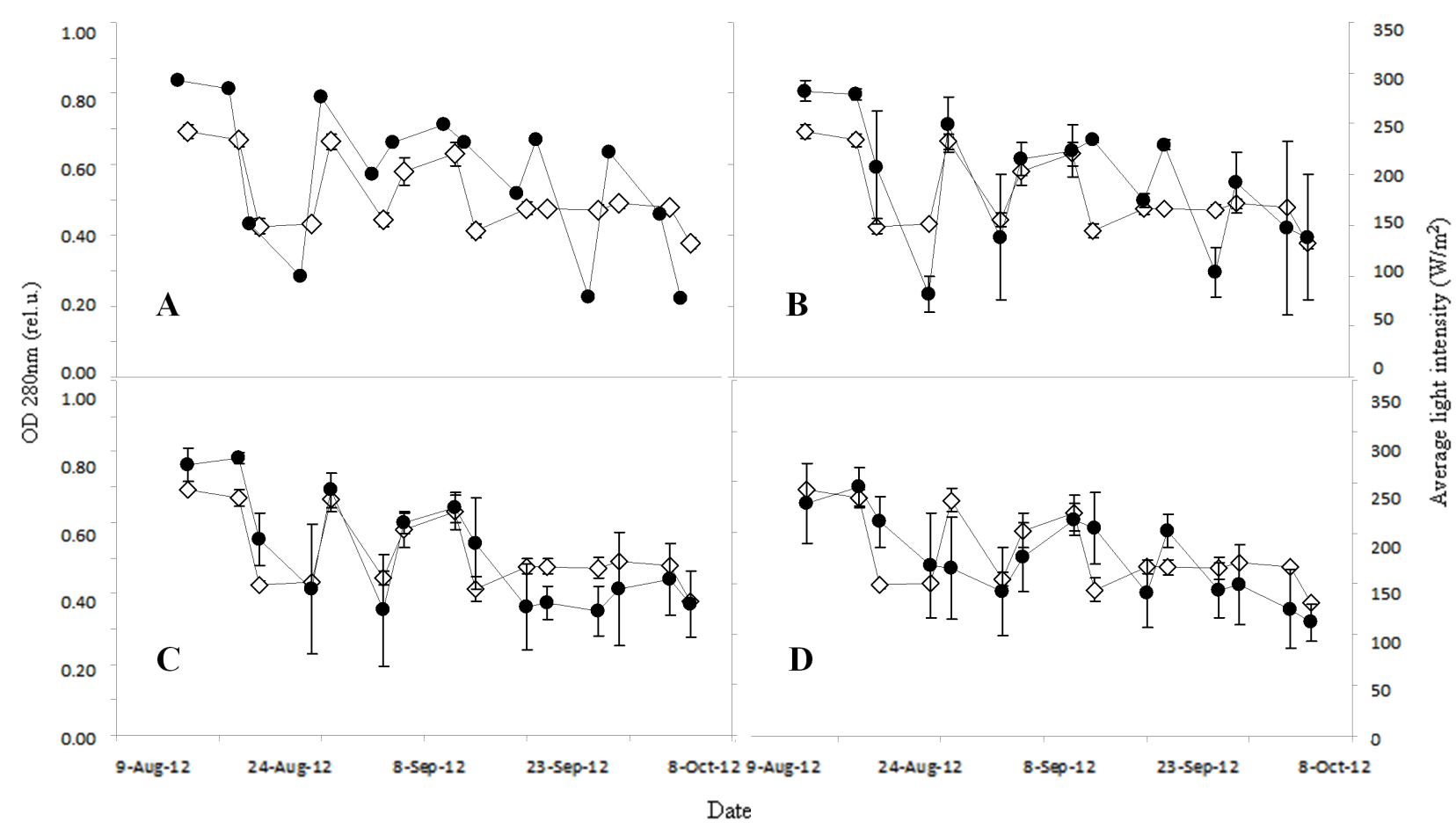

FIGURE 2

Time trend of OD $280 \mathrm{~nm}$ and average light intensity $\left[\mathrm{W} \cdot \mathrm{m}^{-2}\right]$ during the ripening season in 2012. Average value of absorbance at $280 \mathrm{~nm}$ for cv. Chardonnay [ $\diamond$, measured by using spectrophotometer SPECOR 210 from the beginning of the season to harvest time (2012-08-16 to 2012-10-04). Average sunlight intensity [•] in $\mathrm{W} \cdot \mathrm{m}^{-2}$, represented for A: one day before sampling - experiment date [1DE]; B: average value of sunlight intensity two days before sampling - experiment date [2DE]; C: average value of sunlight intensity three days before sampling - experiment date [3DE]; D: average value of sunlight intensity four days before sampling - experiment date [4DE]. Error bars represents standard error of the mean $(\mathrm{n}=6, \mathrm{SEM})$. 
TABLE 3

Regression coefficients $\left(\mathrm{R}^{2}\right)$ of average sunlight intensity and berry sample extracts. Dependence of ambient sunlight intensity on optical density at $280 \mathrm{~nm}$ [OD $280 \mathrm{~nm}$ ], catechin, flavanols and sum of HCA, HBA and stilbene concentrations [mg/kg] respectively. ns, * ,**, *** - non-significant or significant at probability level of $5 \%, 1 \%$ and $0.1 \%$ respectively. Arrows and zero indicate positive ${ }^{[\uparrow]}$, negative ${ }^{[\downarrow]}$ and no ${ }^{[0]}$ covariance between these two variables.

\begin{tabular}{llllll}
\hline & OD 280 nm & $\begin{array}{l}\text { Catechin } \\
{[\mathbf{m g} / \mathbf{k g}]}\end{array}$ & $\begin{array}{l}\text { Flavanols } \\
{[\mathbf{m g} / \mathbf{k g}]}\end{array}$ & $\begin{array}{l}\text { Total polyphenols } \\
{[\mathbf{m g} / \mathbf{k g}]}\end{array}$ & $\begin{array}{l}\text { HCA, HBA + stilbenes } \\
{[\mathbf{m g} / \mathbf{k g}]}\end{array}$ \\
\hline $\mathbf{D E}$ & $0.36^{*}, \uparrow$ & $0.21^{\mathrm{ns}, 0}$ & $0.14^{\mathrm{ns}, 0}$ & $0.06^{\mathrm{ns}, 0}$ & $0.00^{\mathrm{ns}, 0}$ \\
$\mathbf{1 D E}$ & $0.59^{* * *, \uparrow}$ & $0.34^{*, \uparrow}$ & $0.31^{*, \uparrow}$ & $0.23^{\mathrm{ns}, 0}$ & $0.09^{\mathrm{ns}, 0}$ \\
$\mathbf{2 D E}$ & $0.49^{*, \uparrow}$ & $0.38^{*, \uparrow}$ & $0.28^{*, \uparrow}$ & $0.26^{*, \uparrow}$ & $0.15^{\mathrm{ns}, 0}$ \\
$\mathbf{3 D E}$ & $0.67^{* * *, \uparrow}$ & $0.59^{* * *, \uparrow}$ & $0.47^{* *, \uparrow}$ & $0.41^{* *, \uparrow}$ & $0.21^{\mathrm{ns}, 0}$ \\
\hline
\end{tabular}

compounds that are severely affected by UV light in both the grapevine leaves and berries of Chardonnay, while the HCAs are not. Also, Crippen and Morrison (1986) confirmed the effect of sun exposure on the concentration of soluble phenols. They found significant differences between the sunexposed and shaded grapes of Cabernet Sauvignon and an increasing trend in the percentage of phenols from véraison to harvest, which is in accordance with our experimental results.

The novelty of our study consists in the fact that we aimed to provide a more realistic insight into the influence of sunlight regime on the phenolic profiles in vineyards under field conditions in a time dependent manner. Most studies in the past were based on experimental setups that do not occur in the field. As mentioned, several studies have reported the shielding approach, where in some case the UV light was either filtered (e.g. Spayd et al., 2002; Berli et al., 2008; Friedel et al., 2015), or enhanced by using UV lamps (e.g. Petit et al., 2009). Surprisingly, relatively high concentrations of flavonols were also found in the absence of UV light (Keller \& Torres-Martinez, 2004), suggesting their possible role not only in protection against excess UV light, but also in other light-dependent metabolic processes. The significance of our experimental setup consists of keeping the natural light conditions free from manipulation. In this way we could only assume that higher average light intensity comes with higher UV. In contrast to earlier studies (Cortell \& Kennedy, 2006; Zhao et al., 2006), we dealt with a mixture of berries that represents the usual conditions in vineyard management and harvest, i.e. collection of all berries from the cluster with no space for the segregation of particular ones. Undoubtedly, for most modern wineries the main objective is to produce wines of superior quality, thus increasing competitiveness on a national and/or international scale, also in conjunction with reducing input costs. Our study of the temporal influence of ambient sunlight intensity on the phenolic profiles of grapes offers a realistic insight into the interplay between light regimes and a series of secondary metabolites that eventually result in phenolic ripeness. A better understanding of these dynamics will help wine production management and improve the existing strategies to grow higher quality wine grapes in an ever-changing environment.

\section{CONCLUSIONS}

In this work we demonstrate the effects of ambient sunlight on the temporal phenolic profiles of Vitis vinifera L. cv. Chardonnay. Knowing the environmental conditions during one ripening season, a significant correlation was found between the phenolic content and sunlight irradiance from véraison to harvest, while the temporal profiles of these compounds could vary in different ripening seasons. The main novelty of our study consists in the use of field conditions with a non-manipulated light regime, therefore providing realistic, de facto trends for the light dependence of phenolic ripeness. These correlation models between light intensity, analytical description of the phenolic profile (HPLC) and spectrophotometric analysis can contribute to a better understanding of the optimal phenolic ripeness. As a result, this will help lead to an increase in production of higher quality grapes and, consequently, to better-quality final products.

\section{LITERATURE CITED}

Abou-Hussein, S.D., 2012. Climate change and its impact on the productivity and quality of vegetable crops. J. Appl. Sci. Res. 8, 4359-4383.

Adams, D.O., 2006. Phenolics and ripening in grape berries. Am. J. Enol. Vitic. 57, 249-256.

Agati, G., Stefano, G., Biricolti, S. \& Tattini, M., 2009. Mesophyll distribution of 'antioxidant' flavonoid glycosides in Ligustrum vulgare leaves under contrasting sunlight irradiance. Ann. Bot. 104, 853-861.

Bergqvist, J., Dokoozlian, N. \& Ebisuda, N., 2001. Sunlight exposure and temperature effects on berry growth and composition of Cabernet Sauvignon and Grenache in the central San Joaquin Valley of California. Am. J. Enol. Vitic. 52, 1-7.

Berli, F., D’Angelo, J., Cavagnaro, B., Bottini, R., Wuilloud, R. \& Silva, M.F., 2008. Phenolic composition in grape (Vitis vinifera $\mathrm{L}$. Cv. Malbec) ripened with different solar UV-B radiations levels by capillary zone electrophoresis. J. Agric. Food Chem. 56, 2892-2898.

Bogs, J., Ebadi, A., McDavid, D. \& Robinson, S.P., 2006. Identification of the flavonoid hydroxylases from grapevine and their regulation during fruit development. Plant Physiol. 140, 279-291.

Burger, J. \& Edwards, G.E., 1996. Photosynthetic efficiency and photo damage by UV and visible radiation, in red versus green leaf Coleus varieties. Plant Cell Physiol. 37, 395-399.

Conde, C., Silva, P., Fontes, N., Dias, A.C.P., Tavares, R.M., Sousa, M.J., Agasse, A., Delrot, S. \& Gerós, H., 2007. Biochemical changes throughout grape berry development and fruit and wine quality. Food 1, 1-22. 
Coombe, B.G., 1992. Research on development and ripening of the grape berry. Am. J. Enol. Vitic. 43, 101-110.

Cortell, J.M. \& Kennedy, J.A., 2006. Effect of shading on accumulation of flavonoid compounds in (Vitis vinifera L.) Pinot Noir fruit and extraction in a model system. J. Agric. Food Chem. 54, 8510-8520.

Crippen, D.D. \& Morrison, J.C., 1986. The effects of sun exposure on the phenolic con

tent of Cabernet Sauvignon berries during development. Am. J. Enol. Vitic. $37,243-247$.

De Orduña, R.M., 2010. Climate change associated effects on grape and wine quality and production. Food Res. Int. 43, 1844-1855

Dokoozlian, N.K. \& Kliewer, W.M., 1996. Influence of light on grape berry growth and composition varies during fruit development. J. Am. Soc. Hort Sci. 121, 869-874.

Doshi, P., Adsule, P. \& Banerjee, K., 2006. Phenolic composition and antioxidant activity in grapevine parts and berries (Vitis vinifera L.) cv Kishmish Chornyi (Sharad Seedless) during maturation. Int. J. Food Sci. Technol. 41, 1-9.

Downey, M.O., Harvey, J.S. \& Robinson, S.P., 2003. Analysis of tannins in seed and skin of Shiraz grapes throughout berry development. Aus. J. Grape Wine Res. 9, 15-27.

Downey, M.O., Harvey, J.S. \& Simon, R., 2004. The effect of bunch shading on berry development and flavonoid accumulation in Shiraz grapes. Aus. J. Grape Wine Res. 10, 55-73.

Fanzone, M., Zamora, F., Jofré, V., Assof, M. \& Peña-Neira, Á., 2011. Phenolic composition of Malbec grape skins and seeds from Valle de Uco (Mendoza, Argentina) during ripening. Effect of cluster thinning. J. Agric. Food Chem. 59, 6120-6136.

Fraga, H., Malheiro, A.C., Moutinho-Pereira, J. \& Santos, J.A., 2012. An overview of climate change impacts on European viticulture. Food Energy Secur. 1, 94-110.

Frankhauser, C. \& Staiger, D., 2002. Photoreceptors in Arabidopsis thaliana: Light perception, signal transduction and entrainment of the endogenous clock. Planta 216, 1-16.

Frederick, J.E., 1993. Ultraviolet sunlight reaching the earth's surface: A review of recent research. Photochem. Photobiol. 57, 175-178.

Friedel, M., Stoll, M., Patz, C.D., Will, F. \& Dietrich, H., 2015. Impact of light exposure on fruit composition of white 'Riesling' grape berries (Vitis vinifera $\mathrm{L}$.). Vitis 54, 107-116.

Gambuti, A., Capuano, R., Lecce, L., Fragasso, M.G. \& Moio, L., 2009. Extraction of phenolics compounds from 'Aglianico' and 'Uva di Troia' grape skins and seeds in model solutions: Influence of ethanol and maceration time. Vitis 48, 193-200.

Gladstone, E.A. \& Dokoozlian, N.K., 2003. Influence of leaf area density and trellis/training system on the light microclimate within grapevine canopies. Vitis 42, 123-131.

Guifree, A.M., 2013. High performance liquid chromatography-diode array detector (HPLC-DAD) detection of trans-resveratrol: Evolution during ripening in grape berry skins. Afr. J. Agric. Res. 8, 224-229.

Hale, C.R. \& Buttrose, M.S., 1974. Effect of temperature on ontogeny of berries of Vitis vinifera L. cv. 'Cabernet Sauvignon'. J. Am. Soc. Hort. Sci. 99, 390-394.

Hollósy, F., 2002. Effect of ultraviolet radiation on plant cells. Micron 33, 179-197.
Ivanova, V., Stefova, M., Vojnovski, B., Dornyei, A., Márk, L., Dimovska, V., Stafilov, T. \& Kilár, F., 2011. Identification of polyphenolic compounds in red and white grape varieties grown in R. Macedonia and changes of their content during ripening. Food Res. Int. 44, 2851-2860.

Kakani, V.G., Reddy, K.R., Zhao, D. \& Mohammed, A.R., 2003. Effects of ultraviolet-B radiation on cotton (Gossypium hirsutum L.) morphology and anatomy. Ann. Bot. 91, 817-826.

Keller, M. \& Torres-Martinez, N., 2004. Does UV radiation affect winegrape composition? Acta Hortic. 640, 313-319.

Kennedy, J.A., Matthews, M.A. \& Waterhouse, A.L., 2000. Changes in grape seed polyphenols during fruit ripening. Phytochem. 55, 77-85.

Kennedy, J.A., Matthews, M.A. \& Waterhouse, A.L., 2002. Effect of maturity and vine water status on grape skin and wine flavonoids. Am. J. Enol. Vitic. 53, 268-274.

Kliewer, W.M., 1970. Effect of day temperature and light intensity on coloration of Vitis vinifera grapes. J. Am. Soc. Hort. Sci. 95, 693-697.

Kolb, C.A., Kaser, M.A., Kopecký, J., Zotz, G., Reiderer, M. \& Pfundel, E.E., 2001. Effect of natural intensities of visible and ultraviolet radiation on epidermal ultraviolet screening and photosynthesis in grape leaves. Plant Physiol. 127, 863-875.

Kolb, C.A., Kopecký, J., Riederer, M. \& Pfundel, E.E., 2003. UV screening by phenolics in berries of grapevine (Vitis vinifera). Funct. Plant Biol. 30, $1177-1186$

Kumšta, M., Pavloušek, P. \& Kupsa, J., 2012. Phenolic profile in Czech white wines from different terroirs. Food Sci. Biotechnol. 21, 1593-1601.

Lorenz, D.H., Eichhorn, K.W., Bleiholder, H., Klose, R., Meier, U. \& Weber, E., 1995. Growth stages of the grapevine: Phenological growth stages of the grapevine (Vitis vinifera L. ssp. vinifera) - Codes and descriptions according to the extended BBCH scale. Aus. J. Grape Wine Res. 1, 100-103.

McKenzie, R.L., Bjorn, L.O., Bais, A. \& Ilyasad, M., 2003. Changes in biologically active ultraviolet radiation reaching the earth's surface. Photochem. Photobiol. Sci. 2, 5-15.

Pal, D. \& Verma, P., 2013. Flavonoids: A powerful and abundant source of antioxidants. Int. J. Pharm. Pharmac. Sci. 5, 95-98.

Pena-Neira, A., Duenas, M., Duarte, A., Hernandez, T., Estrella, I. \& Loyola, E., 2004. Effects of ripening stages and of plant vegetative vigor on the phenolic composition of grapes (Vitis vinifera L.) cv. Cabernet Sauvignon in the Maipo Valley (Chile). Vitis 43, 51-57.

Pereira, G.E., Gaudillere, J.P., Pieri, P., Hilbert, G., Maucourt, M., Deborde, C., Moing, A. \& Rolin, D., 2006. Microclimate influence on mineral and metabolomic profiles of grape berries. J. Agric. Food Chem. 54, 6465-6775.

Perez-Magarino, S. \& Gonzalez-San Jose, M.L., 2004. Evolution of flavanols, anthocyanins, and their derivatives during the aging of red wines elaborated from grapes harvested at different stages of ripening. J. Agric. Food Chem. 52, 1118-1189.

Petit, A.N., Baillieul, F., Vaillant-Gaveau, N., Jacquens, L., Conreux, A., Jeandet, P., Clément, C. \& Fontaine, F., 2009. Low responsiveness of grapevine flowers and berries at fruit set to UV-C radiation. J. Exp. Bot. $60,1155-1162$

Pirie, A. \& Mullins, M.G., 1976. Changes in anthocyanin and phenolics content of grapevine leaf and fruit tissues treated with sucrose, nitrate, and abscisic acid. Plant Physiol. 58, 468-472.

Pirie, A. \& Mullins, M.G., 1977. Interrelationship of sugars, anthocyanins, total polyphenols and dry weight in the skin of grape berries during ripening Am. J. Enol. Vitic. 28, 204-209.

Price, S., Breen, P., Valladao, M. \& Watson, B., 1995. Cluster sun exposure and quercetin in Pinot noir grapes and wine. Am. J. Enol. Vitic. 46, 187-194. 
Ramos, R., Andrade, P.B., Seabra, R.M., Pereira, C., Ferreira, M.A. \& Faia, M.A., 1999. A preliminary study of non-coloured phenolics in wines of varietal white grapes (códega, gouveio and malvasia fina): Effects of grape variety, grape maturation and technology of winemaking. Food Chem. 67, $39-44$

Reynolds, A.G., Wardle, D.A., Hall, J.W. \& Dever, M., 1995. Fruit maturation of four Vitis vinifera cultivars in response to vineyard location and basal leaf removal. Am. J. Enol. Vitic. 46, 542-558.

Rusjan, D. \& Mikulič-Petkovšek, M., 2015. Phenolic responses in 1-yearold canes of Vitis vinifera L. cv. Chardonnay induced by grapevine yellows. Aus. J. Grape Wine Res. 21, 123-134.

Rusjan, D., Halbwirth, H., Stich, K., Mikulič-Petkovšek, M. \& Veberič, R., 2012a. Biochemical response of grapevine variety 'Chardonnay' (Vitis vinifera L.) to infection with grapevine yellows (Bois noir). Eur. J. Plant Pathol. 134, 231-237.

Rusjan, D., Veberič, R. \& Mikulič-Petkovšek, M., 2012b. The response of phenolic compounds in grapes of variety 'Chardonnay' (Vitis vinifera L.) to the infection by phytoplasma Bois noir. Eur. J. Plant Pathol. 133, 965-974.

Schreiner, M., Mewis, I., Huyskens-Keil, S., Jansen, M.A.K., Zrenner, R., Winkler, J.B., O’Brien, N. \& Krumbein, A., 2012. UV-B induced secondary plant metabolites - potential benefits for plant and human health. Critic. Rev. Plant Sci. 31, 229-240.
Schultz, H., 2000. Climate change and viticulture: A European perspective on climatology, carbon dioxide and UV-B effects. Aus. J. Grape and Wine Res. 6, 2-12.

Šebela, D., Olejníčková, J., Sotolář, R., Vrchotová, N. \& Tř́ska, J., 2014. Towards optical detection of Plasmopara viticola infection in the field. J. Plant Pathol. 96, 309-320.

Singleton, V.L., Timberlake, C.F. \& Lea, A.G.H., 1978. The phenolic cinnamates of white grapes and wine. J. Sci. Food Agric. 29, 403-410

Spayd, S.E., Tarara, J.M., Mee, D.L. \& Ferguson, J.C., 2002. Separation of sunlight and temperature effects on the composition of Vitis vinifera cv. Merlot berries. Am. J. Enol. Vitic. 53, 171-182.

Teixeira, A., Eiras-Dias, J., Castellarin, S.D. \& Gerós, H., 2013. Berry phenolics of grapevine under challenging environments. Int. J. Mol. Sci. 14, 18711-18739.

Versari, A., Parpinello, G.P., Tornielli, G.B., Ferrarini, R. \& Giulivo, C., 2001. Stilbene compounds and stilbene synthase expression during ripening, wilting and UV treatment in grape cv. Corvina. J. Agric. Food Chem. 49, 5531-5536

Zhao, X.J., Wang, X., Liu, B., Li, J., Sun, Y.X. \& Shu, H.R., 2006. Effect of cluster thinning on catechins in berries of Vitis vinifera cv. Cabernet Sauvignon. Vitis 45, 103-104. 